\title{
Progress in Vitreo Retinal Surgery
}

\author{
Simona Delia Nicoară* \\ Professor of Ophthalmology, Emergency County Hospital, Romania
}

Received: 㯺 January 07, 2019; Published: 監 January 18, 2019

*Corresponding author: Simona Delia Nicoară, Professor of Ophthalmology, Emergency County Hospital, Cluj-Napoca, Romania

\section{Opinion}

Modern vitreo-retinal surgery consists in pars plana vitrectomy (PPV), which basically aims to relieve all the vitreo-retinal tractions, with minimal disturbance on the underlying retina [1]. The first indication for PPV in a closed system was the vitreous hemorrhage in a diabetic patient and it was performed by Robert Machemer, in 1972. For three decades, PPV was performed with the 20-gauge $(G)$ system. Starting 2004, a new vitrectomy concept became popular: the minimally invasive vitrectomy system (MIVS): 23G, 25G and 27G $[2,3]$. MIVS was developed with the aim to make PPV a safer and less traumatizing procedure and it was followed by the decrease of tissue damage and the shortening of surgery time. Since the sutures were no longer needed, the suture-related inflammation was eliminated and the healing period became much shorter and comfortable $[1,4]$. The drawbacks related to the smaller size of the instruments had to be overcame by the development of new instruments $[1,5,6]$.

\section{Fluidics During Surgery}

The flow measures the efficiency of vitrectomy. Flow rate is determined by the following factors: the diameter of the cutter's opening, the duty cycle, the vacuum, the viscosity of the material to be aspirated, the movement of the blade, the internal diameter of the cutter's lumen [1,7]. When a smaller caliber instrument is used, the flow rate decreases and surgery is longer. The pressure at the opening of the cutter sets the vitreous removal rate: if it is too low, the removal of the vitreous takes longer and if it is too high, there is the risk of retinal injury through traction at the vitreo-retinal junction $[1,5,6]$. The rate of vitreous removal is influenced by the following factors: the infusion pressure, the aspiration pressure, the duty cycle of the vitrector and probe geometry $[1-2,8]$. Poisseuille's law rules the intraoperative fluidics in MIVS: $\mathrm{Q}=\Delta \mathrm{P} \pi \mathrm{R}^{4} / 8 \mu \mathrm{L}$, in which $\mathrm{Q}=$ flow, $\Delta \mathrm{P}=$ pressure gradient along the tube, $\mathrm{R}=$ radius of the tube, $\mu$ = viscosity of the fluid in the tube, $L=$ length of the tube [8]. The options are: to increase the infusion pressure and the aspiration pressure and to modify the duty cycle of the cutter.
Increasing the infusion pressure decreases the blood flow through the central retinal artery and the choriocapillaris, which may be dangerous, especially in the patients suffering from vascular diseases of the retina. The maximum level of the aspiration pressure is set on the machine console and controlled by the surgeon, by acting on the foot pedal. When a small gauge vitrectomy instrument is used, in order to achieve reasonable rates of vitreous removal, higher aspiration is needed. The duty cycle of the cutter is the ratio between the intervals during which the cutter is open and closed. If the duty cycle of the cutter is modified, such as the port is open for a longer time, higher flow rates are generated. This modification compensates for the decreased flow associated with the small size ports of the 23G, 25G and 27G cutters [1-2,5,6]. Features of the cutters used with MIVS. The main advantages of the MIVS come from the features of the cutters with smaller side ports that are able to work very close to the retina, with no risk to incarcerate it in the cutter. However, the small port opening limits the ability of the cutter to aspirate and hold the vitreous $[1,2,7,8]$. In order to get close to the retina with minimal risks, the port opening was localized very close to the tip. Due to the port - based flow resistance, vitrectomy is very safe.

\section{Mechanical Considerations Specific to the MIVS}

The small gauge instruments are more flexible which makes the removal of the peripheral vitreous more laboriuos. Therefore, stiffer instruments are designed for MIVS $[1,2,5,6]$. The geometry of the cannula requires a special design for the accessory instruments: scissors, forceps, picks. Their tips must be shorter and angulated, which makes them less efficient in dissecting and cutting epiretinal membranes. Endoillumination considerations related to the MIVS. During small gauge vitrectomy procedures, the smaller diameter of the probes leads to the decrease of the light level. In order to compensate for this disadvantage, high intensity xenon and metal halide light sources were developed [1,2]. 


\section{Advantages of the MIVS}

MIVS has the following advantages over the 20G vitrectomy: less damage to the ocular tissues, less circulating fluid in the globe, less inflammation and discomfort for the patient, shorter surgery and no need for sutures $[1,2]$.

\section{References}

1. Nagpal M, Paranjpe G, Jain P, Videkar R (2012) Advances in small-gauge vitrectomy, Taiwan Journal of Ophthalmology 2: 6-12.

2. Thompson JT (2011) Advantages and limitations of small gauge vitrectomy, Survey of Ophthalmology 56(2): 162 -172.

3. Yoon YH, Kim DS, Kim JG, Hwang JU (2006) Sutureless vitrectomy surgery using a new 25-gauge transconjunctival system. Ophthalmic Surg Lasers Imaging 3(1)7: 12-9.

ISSN: 2574-1241

DOI: $10.26717 / B J S T R .2019 .13 .002380$

Simona Delia Nicoară. Biomed J Sci \& Tech Res

cC) (i) This work is licensed under Creative

BY Commons Attribution 4.0 License

Submission Link: https://biomedres.us/submit-manuscript.php
4. Lakhanpal RR, Humayan MS, De Juan E Jr, Lim JI, Chong LP, et al. (2005) Outcomes of 140 consecutive cases of 25-gauge transconjunctival surgery for posterior segment disease. Ophthalmology 112(5): 817-824.

5. Williams GA (2008) 25-, 23-, or 20-gauge instrumentation for vitreous surgery? Eye 22: 1263-1266.

6. Spirn MJ (2009) Comparison of 25-, 23-, and 20-gauge vitrectomy. Curr Opin Ophthalmol 20(3): 195-199.

7. Guttman C (2010) Intraoperative control comprehension of vitrectomy fluidics underlies safe and effective surgery. Ophthalmology Times 2: 18-19.

8. Magalhaes O Jr, Chong L, De Boer C, Bhadri P, Kerns R, et al. (2008) Vitreous dynamics: vitreous flow analysis in 20-, 23-, and 25-gauge cutters. Retina 28 (2): 236-241.

$\begin{array}{ll}\text { BIOMEDICAL } & \text { Assets of Publishing with us } \\ \text { RESEARCHES } & \text { - Global archiving of articles } \\ \text { - Immediate, unrestricted online access } & \text { - Rigorous Peer Review Process } \\ & \text { - Authors Retain Copyrights }\end{array}$

